\title{
Differential behaviour of Anopheles gambiae sensu stricto (Diptera: Culicidae) to human and cow odours in the laboratory
}

\author{
H.V. Pates ${ }^{1,2}$, W. Takken ${ }^{1 *}$, K. Stuke ${ }^{1}$ and C.F. Curtis ${ }^{2}$ \\ ${ }^{1}$ Laboratory of Entomology, Wageningen Agricultural University, PO Box \\ 8031, $6700 \mathrm{EH}$ Wageningen, The Netherlands: ${ }^{2}$ London School of Hygiene \\ and Tropical Medicine, Keppel Street, London, WC1E 7HT, UK
}

\begin{abstract}
A dual port olfactometer was used to study the response of Anopheles gambiae Giles sensu stricto to odours of human and animal origin. Human odour consisted of human skin emanations collected on a nylon stocking, which was worn for $24 \mathrm{~h}$. This was tested alone or together with $4.5 \%$ carbon dioxide, the concentration in human and cattle breath. Cattle odours consisted of cow skin emanations and / or carbon dioxide. Cow skin emanations were collected by tying a nylon stocking ('cow sock') around the hind leg of a cow for $12 \mathrm{~h}$. Anopheles gambiae s.s. was consistently highly attracted by human odour, which is consistent with the high degree of anthropophily in this mosquito. Anopheles gambiae s.s. was not attracted by human or cattle equivalent volumes of carbon dioxide and this gas did not enhance the effect of human skin residues. Furthermore, A. gambiae s.s. showed a high degree of aversion to cow odour. When human odour and cow odour were tested together in the same port, mosquitoes were still highly attracted, indicating that whilst cattle odour may deter A. gambiae s.s., these mosquitoes can detect human odour in the presence of cattle odour. It was concluded that carbon dioxide plays a minor role in the host seeking behaviour of $A$. gambiae s.s., whilst host specific cues such as human skin residues play a major role and very effectively demonstrated anthropophilic behaviour in the laboratory.
\end{abstract}

\section{Introduction}

Anopheles gambiae Giles sensu stricto (Diptera: Culicidae) is the main malaria vector in Africa. It is one of the sibling species in the Anopheles gambiae complex. The sibling species are morphologically identical, do not interbreed in the wild and are characterized by markedly different behaviour. Most populations of $A$. gambiae sensu lato in and around continental Africa are composed of A. gambiae s.s. and/or

*Fax: 0031317484821

E-mail: willem.takken@users.ento.wau.nl
Anopheles arabiensis Patton, two freshwater breeding species both vectors of malaria, that can occur separately or together (White, 1974). These populations occur sympatrically with the saltwater breeding species Anopheles melas Theobald in West Africa and Anopheles merus Dönitz in East Africa. Anopheles bwambae White has only been found breeding in the mineral water swamps of the Semliki forest in Bwamba county, Uganda (White, 1985). Anopheles quadriannulatus Theobald, the other freshwater species in the complex, has been reported in the highlands of Ethiopia and extensively in southern Africa (White, 1974). However, a recent study by Hunt et al. (1998) has distinguished the Ethiopian population 
as a new species, and until it has been formally described it was designated as $A$. quadriannulatus species $\mathrm{B}$. The diverse bloodfeeding behaviour exhibited by the sibling species of this complex is best illustrated by two members of the complex. Anopheles gambiae s.s. is the most anthropophilic member of the complex, hence its efficiency as a malaria vector. However, A. quadriannulatus is highly zoophilic and therefore not a vector of malaria and considered to be of no medical importance.

Laboratory studies using a wind tunnel or an olfactometer have demonstrated the role of human odour in the host-seeking behaviour of A. gambiae s.s. (Takken \& Knols, 1990; Knols \& De Jong, 1996; Braks et al., 1997), although until relatively recently most of the work on host selection in A. gambiae s.s. has been carried out in the field (Gillies, 1967; Costantini et al., 1993, 1998; Mboera et al., 1997; Takken \& Knols, 1999). These studies demonstrated that host selection in A. gambiae is mediated by host odours and that recorded host preferences are genetically fixed. In field studies, A. gambiae s.s. consistently exhibits a high degree of anthropophily, even when presented with odour plumes consisting of mainly cattle odour (Coluzzi et al., 1975). However, on other occasions this anthropophilic behaviour appears to be less rigid (Diatta et al., 1998). The purpose of the present study was to investigate the anthropophilic tendencies in A. gambiae s.s. using human and cattle odour by choice tests in an olfactometer.

\section{Materials and methods}

\section{Mosquito colony}

The A. gambiae s.s. colony at Wageningen University, The Netherlands, originated in Liberia in 1987 and has been reared on human blood since 1988. Adult mosquitoes were kept in $30 \mathrm{~cm}$ cube gauze cages at $27 \pm 1^{\circ} \mathrm{C}$ and $80 \%$ relative humidity, with a $12 \mathrm{~h}$ scotophase period consisting of a sharp transition from dark to light. Adults were provided with a $6 \%$ glucose solution and offered a blood meal twice weekly for $10 \mathrm{~min}$ from a human arm. A cone of damp white filter paper was provided for oviposition. Larvae were reared in plastic trays and fed daily on Tetramin ${ }^{\circledR}$ baby fish food. Pupae were removed daily from the trays and allowed to emerge inside the adult cage.

\section{Olfactometer bioassay}

An olfactometer was used to study the behavioural response of teneral adult female mosquitoes to different odour stimuli. The olfactometer (fig. 1) consisted of a transparent flight chamber $(1.6 \times 0.6 \times 0.6 \mathrm{~m})$ through which conditioned, humidified air $\left(27 \pm 0.5^{\circ} \mathrm{C}, 70 \pm 5 \% \mathrm{rh}\right)$ was passed. The air was passed through a charcoal filter to remove all traces of organic compounds and entered the chamber through two small ports $(5 \mathrm{~cm}$ in diameter, horizontally aligned and $30 \mathrm{~cm}$ apart). The ports were connected to the upwind end of the flight chamber, which consisted of a white Trespa ${ }^{\circledR}$ board containing two circular holes, via a glass trapping device that also served to hold the odours (Knols et al., 1994). The air speed was regulated to 21 $\pm 1 \mathrm{~cm} \mathrm{~s}^{-1}$ and passed through a panel of mosquito gauze (mesh width $1 \mathrm{~mm}$ ) at the downwind end. A releasing cage containing the test mosquitoes was fixed to a hole in the centre of the mosquito gauze. The temperature of the experimental room was maintained at $26 \pm 1^{\circ} \mathrm{C}$ with a relative humidity of $55 \pm 5 \%$. Nine 60 Watt light bulbs arranged in rows on the roof of the olfactometer provided conditions equivalent to moonlight (6 Lux).

\section{Odours}

Human skin emanations, cow skin emanations and carbon dioxide were used as odour stimuli. Based on the known role of human foot odour in the host location of $A$. gambiae s.s. (De Jong \& Knols, 1995) nylon stockings were used to collect skin emanations from a human foot. The same human was used to collect foot odour for each series of experiments. The stocking was worn for $24 \mathrm{~h}$ and placed in a clean glass jar before use in an experiment. The same procedure was used to collect cow skin emanations. A nylon stocking was tied around the hind leg of a cow just underneath the hock, for $12 \mathrm{~h}$ and placed in a clean glass jar for storage before and between experiments. Collecting cow skin odours in this way was simple and fast. Cow skin emanations were obtained from the same cow in each case. Both 'cow' and 'human' stockings were laid flat inside the glass traps. Although it was realized that the degree of attraction of mosquitoes to different humans might vary due to differences in volatile emanations, it was considered appropriate to use the same human host and the same cow throughout the study to obtain more accurate comparisons between experiments.

Since the concentration of carbon dioxide exhaled by both humans and cows is $4.5 \%$, a pre-prepared mixture of 4.5\% carbon dioxide in synthetic air (Hoek-Loos, The Netherlands) was used. The carbon dioxide was pumped from the gas cylinder into a 1001 Tedlar ${ }^{\circledR}$ gas-sampling bag approximately $20 \mathrm{~h}$ before use. Ten millilitres of distilled water was added to the bag to obtain a near saturated moisture level. The carbon dioxide was then pumped through Teflon tubing ( $5 \mathrm{~mm}$ width) via a flowmeter (Shorate, Brooks Instrumental B.V., The Netherlands), into the glass traps at either $230 \mathrm{ml} \mathrm{min}{ }^{-1}$ (human equivalent) or at $1000 \mathrm{ml} \mathrm{min}^{-1}$ (cow equivalent).

\section{Experimental procedure}

All experiments took place towards the end of the scotophase. Thirty 5-8-day-old females, which had not been blood-fed were used in each experiment. Mosquitoes were randomly picked from their cage $15 \mathrm{~h}$ before experiments began and placed in a releasing cage with access to distilled water via damp cotton wool placed on the gauze. The sequence of odour combinations tested was randomized on the same test day and between days (see figs 2, 3 and 4 for odour combinations tested). Test stimuli were also alternated between right and left ports to rule out any positional effects. Experiments with no odours in either port tested the symmetry of the trapping system. Mosquitoes were left inside the olfactometer for a total of $20 \mathrm{~min}$, after which they were considered to have responded to a test odour if they had entered a trap. Trapped mosquitoes were anaesthetized using $100 \%$ carbon dioxide and counted at the end of the experiment. Surgical gloves were worn throughout the experimental procedure to avoid contamination of any of the equipment. 


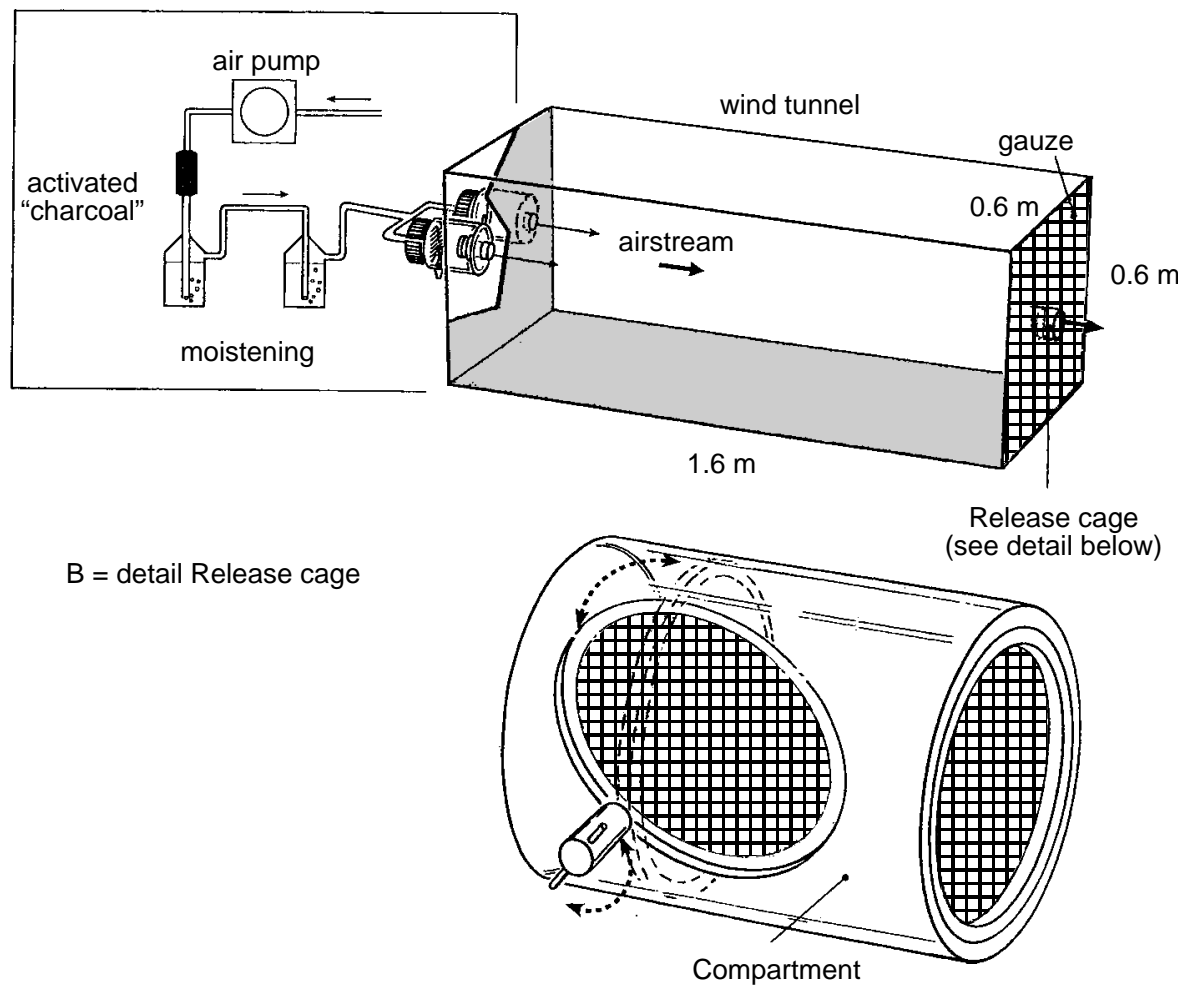

Fig. 1. Diagram of the dual port olfactometer (A) (modified after Braks \& Takken, 1999) and mosquito release cage (B). Air was cleaned by passing it over activated charcoal and moistened by passing it through distilled water. Odour stimuli were placed inside or pumped into the glass trapping devices. Mosquitoes were released from container (B) at the downwind end.

\section{Statistical analysis}

The attractiveness of a stimulus in a two-choice test was determined by the proportion of mosquitoes caught by that stimulus. These proportions were transformed into arcsines of the square roots for analysis. Differences between the total response amplitudes of treatments, and differences between separate trap catches with a certain stimulus were analysed using ANOVA and contrasted by a Tukey test. Differences within each two-choice test were analysed with a chi-square test using the total number of mosquitoes caught after six replicates.

\section{Results}

The majority of mosquitoes left the releasing cage and flew upwind towards the odour source $(98.7 \%$ of 3660 mosquitoes tested). Any mosquitoes that were left in the releasing cage at the end of an experiment were counted and the actual number of mosquitoes released, adjusted accordingly. No mosquitoes escaped from a trap once they had entered. There was no effect of day on the total catch size obtained with each experiment $(P>0.05)$. Control experiments ('no odour') showed that the olfactometer was symmetrical (i.e. there was no preference for the left or the right port), since equal numbers of mosquitoes entered each port. The results for each trial are presented in figs 2,3 and 4 .

\section{Response to skin emanations}

The total number of mosquitoes responding to human odour baits was significantly higher than the control (no odour vs. no odour) (fig. 2-I). However, the total number of mosquitoes responding to cow odour was not significantly different from the control (fig. 2-III). Human skin emanations from a worn nylon stocking were highly attractive to $A$. gambiae s.s. females. Significantly more mosquitoes entered the human odour port when tested against cow odour (fig. 2IV and III) but there was no significant difference between the number of mosquitoes entering the cow odour port when 'no odour' was the alternative choice. Significantly more mosquitoes entered the port containing the human + cow odour combination than either the no-odour or cow-odour port, i.e. the presence of the cow odour together with the human odour did not deter trap entry. There was no significant difference between a choice for human odour alone and human + cow odour combination. However, when cow odour was tested against the combined human + cow odour, significantly more mosquitoes selected the port with the combined odours.

\section{Response to carbon dioxide}

Significantly fewer mosquitoes responded in total in the no odour vs. carbon dioxide (human equivalent) experiment 


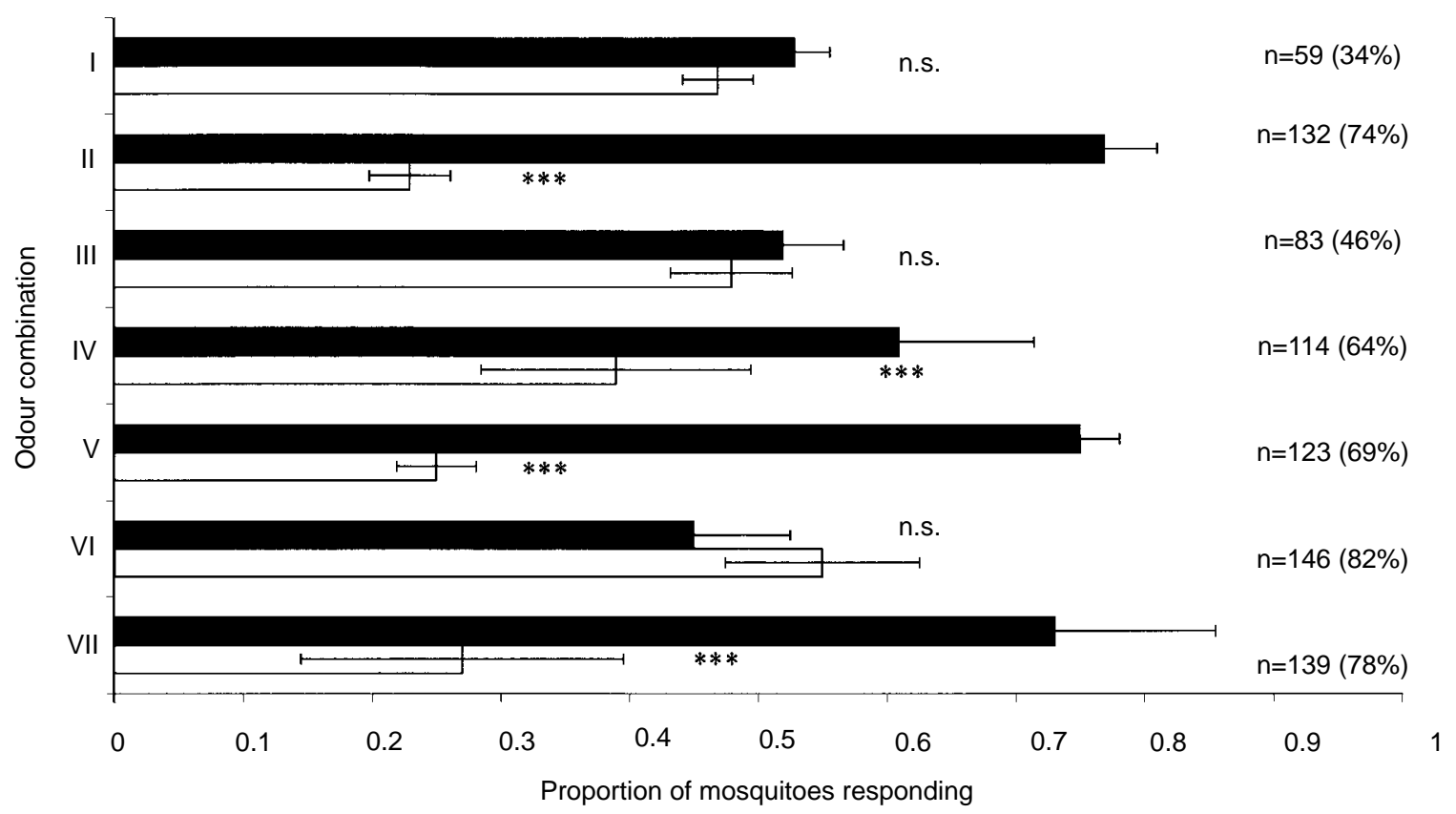

$\begin{array}{lll}\text { Test } & \text { Port 1 } & \text { Port } 2 \\ \text { I } & \text { no odour } & \text { no odour } \\ \text { II } & \text { human odour } & \text { no odour } \\ \text { III } & \text { cow odour } & \text { no odour } \\ \text { IV } & \text { human odour } & \text { cow odour } \\ \text { V } & \text { human + cow odour } & \text { no odour } \\ \text { VI } & \text { human + cow odour } & \text { human odour } \\ \text { VII } & \text { human + cow odour } & \text { cow odour }\end{array}$

Fig. 2. Response of Anopheles gambiae s.s. to skin emanations. The total proportion of mosquitoes flying into either test port after six replicates is shown. Asterisks mark significant differences between the total number trapped in port 1 or port 2 ( $\chi^{2}$ test: n.s.: $P>0.05$ : not significant, ${ }^{* * *} P<0.001$ ). $\mathrm{n}=$ total number of mosquitoes entering both traps (also expressed in parentheses as the percentage mosquitoes responding of the total number of mosquitoes released after six replicates). Error bars show $95 \%$ confidence limits. The table below the graph indicates the odour combination tested.

(ANOVA, $P<0.001$ ) (fig. 3-I), which concurs with previous findings (W. Takken, unpublished). When carbon dioxide was released at human equivalent volumes $\left(230 \mathrm{ml} \mathrm{min}^{-1}\right)$, significantly more mosquitoes entered the no odour port $(P$ $<0.05$ ) (fig. 3-II). There was no effect of carbon dioxide on the response to human odour, whether the compound was released from the opposite port or in combination with human odour. When carbon dioxide was released at cow equivalent volumes $\left(1000 \mathrm{ml} \mathrm{min}{ }^{-1}\right)$, catches were almost three times higher in the no odour port compared with the carbon dioxide port $(P<0.001)$ (fig. 4-I). However, significantly more mosquitoes entered both the no odour and carbon dioxide ports alone than the cow odour + carbon dioxide port. When human odour was tested against cow odour + carbon dioxide, significantly more mosquitoes entered the human odour port (ANOVA, $P<0.05$ ) (fig. 4-VI). The addition of carbon dioxide to the human odour did not significantly increase the entry response, but the addition of carbon dioxide to the cow odour resulted in significantly fewer mosquitoes entering that port. In all tests (except human odour vs. cow odour + carbon dioxide (see fig. 4 -VI)) where human and cow odour were released simultaneously in the olfactometer, the addition of carbon dioxide to either stimulus did not affect the attractive effect of human odour. These results indicate that carbon dioxide may have an inhibitive effect, such that it deters trap entry.

\section{Discussion}

The olfactometer is a useful bioassay for demonstrating host-seeking behaviour in the laboratory. The results presented here show consistent anthropophilic behaviour in a strain of $A$. gambiae s.s. that has been laboratory maintained for 11 years. Collection of human skin residues using nylon stockings was simple, proved to be a good stimulus and produced highly repeatable results. Collection of cow skin residues using nylon stockings was also effective. Previously, T. Dekker and W. Takken (unpublished) showed that skin emanations could be used to differentiate behaviour between $A$. gambiae s.s. and $A$. quadriannulatus. The results showed that even in the absence of odour, a considerable proportion of A. gambiae entered the 


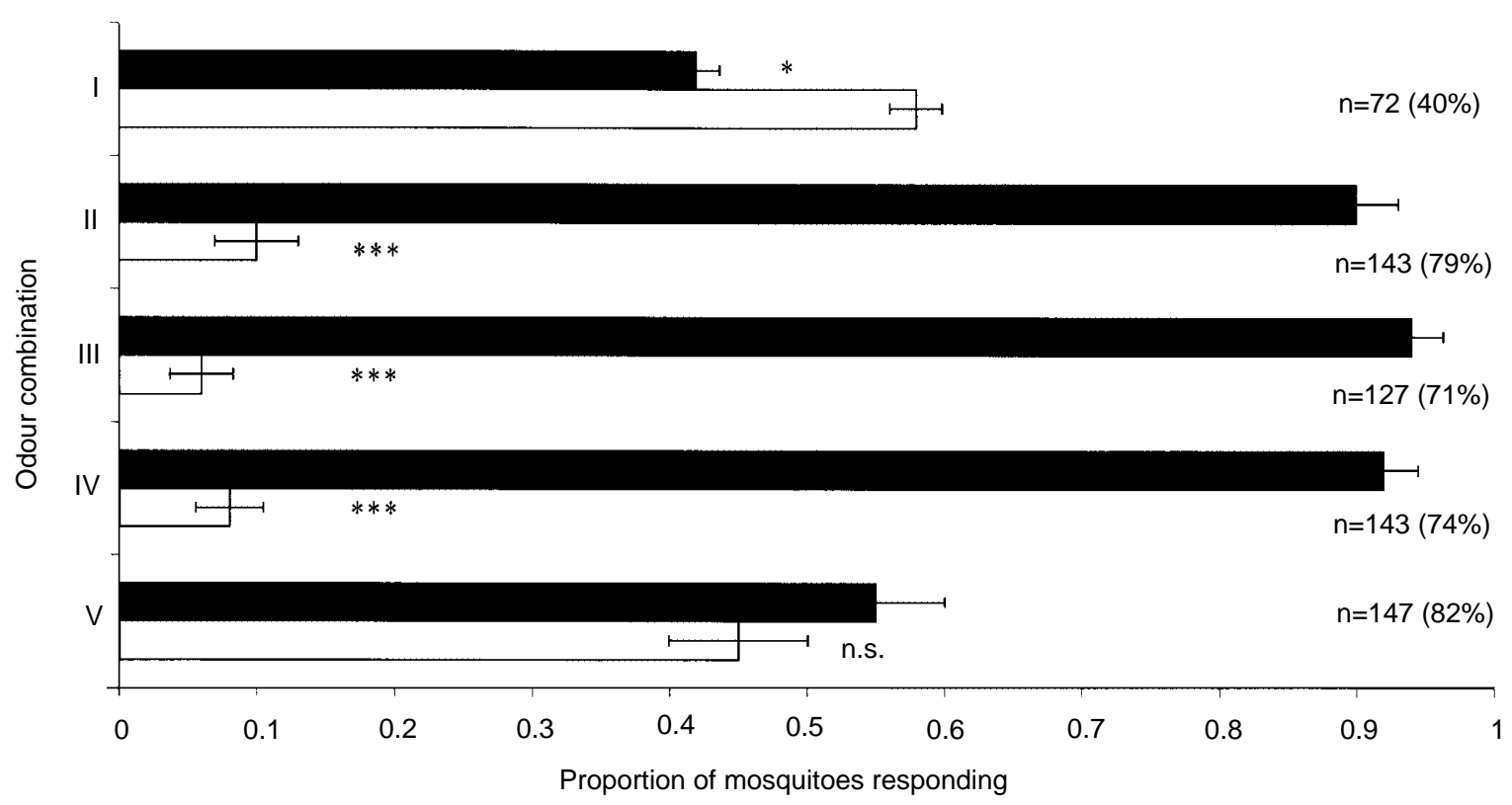

$\begin{array}{lll}\text { Test } & \text { Port } 1 \square & \text { Port } 2 \square \\ \text { I } & \mathrm{CO}_{2}(230 \mathrm{ml} \mathrm{min}-1) & \text { no odour } \\ \text { II } & \text { human odour }+\mathrm{CO}_{2} & \text { no odour } \\ \text { III } & \text { human odour }+\mathrm{CO}_{2} & \mathrm{CO}_{2} \\ \text { IV } & \text { human odour } & \mathrm{CO}_{2} \\ \text { V } & \text { human odour }+\mathrm{CO}_{2} & \text { human odour }\end{array}$

Fig. 3. Response of Anopheles gambiae s.s. to human equivalent volumes of carbon dioxide $\left(230 \mathrm{ml} \mathrm{min}^{-1}\right)$. $\left(\chi^{2}\right.$ test: $\mathrm{n} . \mathrm{s.:} P>0.05$ : not significant, $\left.{ }^{*} P<0.05,{ }^{* * *} P<0.001\right)$. See fig. 2 for full explanation.

upwind traps, a behaviour that is different in Aedes aegypti (Linnaeus) (Diptera: Culicidae), which under similar conditions hardly responds to clean air (Klowden \& Lea, 1978; Geier et al., 1996).

These results showed that cow odour was not attractive to Anopheles gambiae s.s. and human odour was highly attractive, as would be expected with such an anthropophilic mosquito. Previous laboratory studies showed attraction of A. gambiae s.s. to human sweat (Braks et al., 1997; Braks \& Takken, 1999), human equivalent concentrations of acetone offered in combination with carbon dioxide (Takken et al., 1997) and odours of non-human origin arising from the production of fatty acids by the bacteria present on Limburger cheese (Knols \& De Jong, 1996). Similar fatty acids are produced by microorganisms present on the human skin and chemical analyses of the composition of Limburger cheese odour and human foot odour have shown a marked similarity (Knols et al., 1997). De Jong and Knols (1995) demonstrated that A. gambiae s.s. preferentially bite the feet and ankles of a naked, seated, motionless human host, unless the feet and ankles had been washed with an anti-bacterial soap, which significantly altered the biting site distribution. Various field studies have also demonstrated the attractiveness of whole human baits to A. gambiae s.s.
(Costantini et al., 1993, 1996; Knols et al., 1995; Mboera et al., 1997).

Costantini et al. (1998) demonstrated the aversion of $A$. gambiae s.s. to calf odour in Burkina Faso when sampling the mosquito population using odour baited entry traps. Identification of the A. gambiae s.l. samples collected revealed that the human baited trap contained 52\% A. arabiensis and $48 \%$ A. gambiae s.s. whereas the calf baited trap contained $92 \%$ A. arabiensis and $8 \%$ A. gambiae s.s. In this olfactometer study, the aversion of $A$. gambiae s.s. to cattle odour was demonstrated by the reluctance to enter ports containing cow odour. Indeed, the presence of cow odour often led to an increase in the catch in the opposing port. However, this should not be considered as a repellent effect of the cow odour since if it were repellent, one would expect a reduction in the number of mosquitoes entering the port containing the human + cow odour combination, yet the percentage of mosquitoes entering this port was similar to the percentage entering human odour ports (in human odour vs. no odour experiments). This suggests that the mosquito can detect human odour in the presence of cattle odour when the two stimuli are presented simultaneously and that in the presence of human odour, A. gambiae is not 'repelled' by cattle odour. This is the first laboratory 


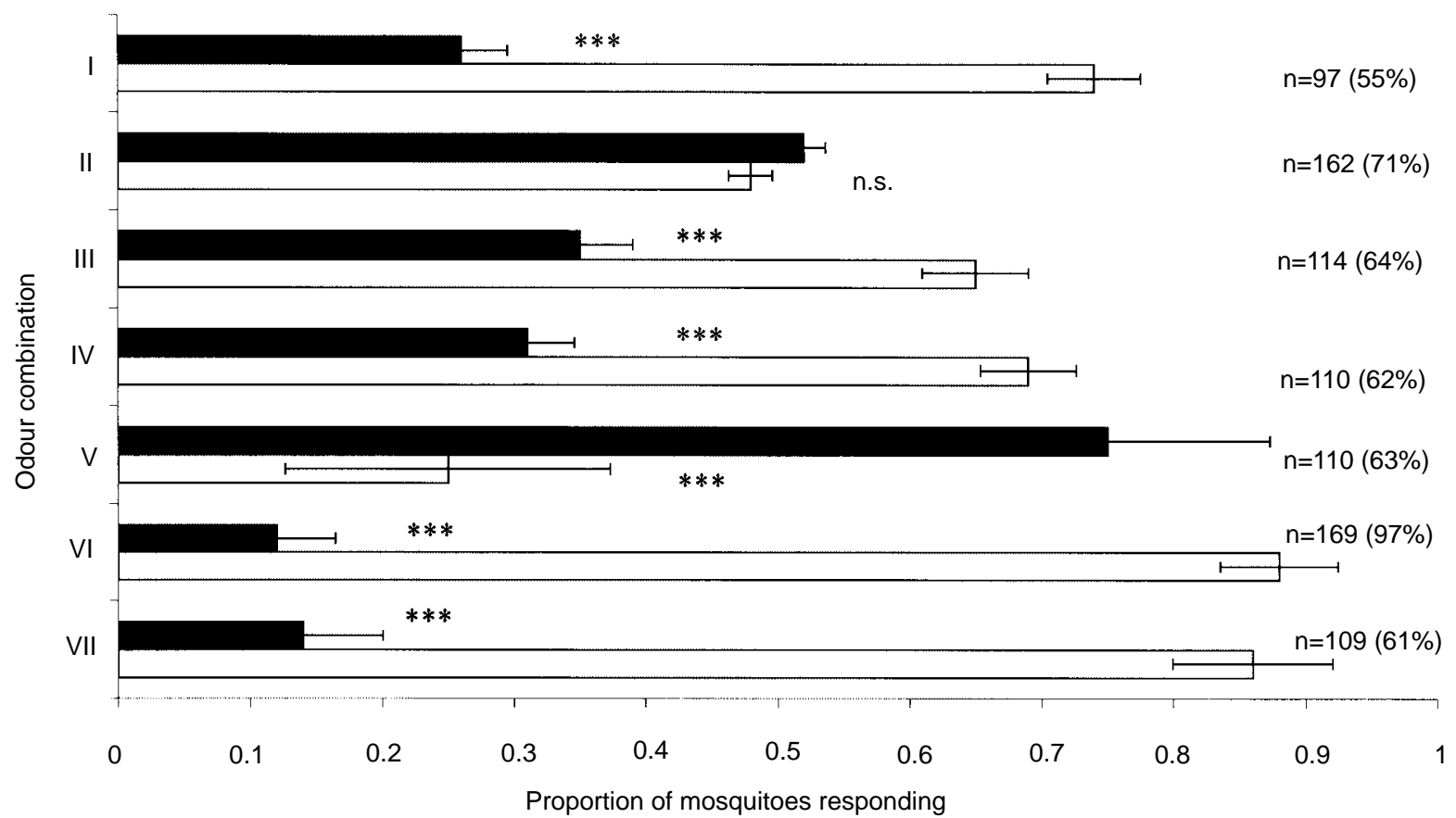

$\begin{array}{lll}\text { Test } & \text { Port 1 } & \text { Port } 2 ~ \\ \text { I } & \mathrm{CO}_{2}(1000 \mathrm{ml} \mathrm{min}-1) & \text { no odour } \\ \text { II } & \text { cow odour } & \mathrm{CO}_{2} \\ \text { III } & \text { cow odour }+\mathrm{CO}_{2} & \mathrm{CO}_{2} \\ \text { IV } & \text { cow odour }+\mathrm{CO}_{2} & \text { no odour } \\ \text { V } & \text { human odour }+\mathrm{CO}_{2} & \text { no odour } \\ \text { VI } & \text { cow odour }+\mathrm{CO}_{2} & \text { human odour } \\ \text { VII } & \text { cow odour }+\mathrm{CO}_{2} & \text { human odour }+\mathrm{CO}_{2}\end{array}$

Fig. 4. Response of Anopheles gambiae s.s. to calf equivalent volumes of carbon dioxide $\left(1000 \mathrm{ml} \mathrm{min}^{-1}\right)$. $\left(\chi^{2}\right.$ test: $\mathrm{n} . \mathrm{s.:} P>0.05: \mathrm{not}$ significant, $\left.{ }^{* * *} P<0.001\right)$. See fig. 2 for full explanation.

confirmation of field observations by White \& Rosen (1973) and Coluzzi et al. (1975) that showed A. gambiae s.s. can locate a human host surrounded by cattle.

Anopheles gambiae s.s. was not attracted to carbon dioxide offered at either human equivalent or cow equivalent volumes, and cow equivalent volumes of carbon dioxide appeared to have a more deterrent effect than human volumes. Carbon dioxide at cow or human equivalent volumes did not enhance the effect of human skin emanations (i.e. it did not increase the entry response (see fig. 2-II; fig. 3-II and fig. 4-V)). However, carbon dioxide at cow equivalent volumes did increase the deterrent effect of cow odour. Results from olfactometer studies by Mboera et al. (1998) with Culex quinquefasciatus Say (Diptera: Culicidae), another highly anthropophilic mosquito, observed no synergistic effect of carbon dioxide in combination with human skin emanations. De Jong \& Knols (1995) tested human breath and carbon dioxide $(3.56 \%)$ in a windtunnel olfactometer and found no attraction of $A$. gambiae s.s. to either stimulus. A field study by Mboera et al. (1997) in Tanzania, caught significantly fewer mosquitoes in a tent into which carbon dioxide was pumped than in a human odour baited tent. Costantini et al. (1996) also caught significantly more A. gambiae s.l. in human odour baited entry traps than in carbon dioxide baited traps, placed side by side.

It is considered that carbon dioxide may play an activating role causing the mosquito to engage in upwind anemotaxis and that carbon dioxide is a more important olfactory stimulus for zoophilic species than it is for anthropophilic species (Gillies, 1980; Mboera \& Takken, 1997; Takken et al., 1997; Dekker \& Takken, 1998). In field experiments, it was found that $A$. gambiae s.s. was attracted to carbon dioxide although this compound alone could never substitute for human skin emanations that appear to be more important odour cues (Costantini et al., 1996). There was no significant difference in the total entry response in each experiment where carbon dioxide was used in combination with human odour, with the exception of human odour vs. cow odour + carbon dioxide (offered at calf equivalents) (fig. 4-VI). This anomaly is possibly explained by the absence of carbon dioxide in the human odour port that made trap entry easier. Alternatively, the cow odour + carbon dioxide odour combination may deter mosquitoes 
from entering that port, resulting in an increase in the number that enter the human odour port. Recently, Dekker et al. (in press) found that the turbulence of the carbon dioxide odour plume greatly affected trap entry. It was observed that homogeneously-mixed carbon dioxide caused significantly reduced entry responses, which is similar to the response seen in this study. The inhibitive effect of carbon dioxide was expressed with the compound as the only stimulus and in combination with human skin emanations. In the present study, there was a similar inhibitive effect of carbon dioxide alone (fig. 3-I, fig. 4-I) but not when human skin emanations were present. As we did not control for the turbulence of the odour plume, it may have been possible that the effect of carbon dioxide on the flight behaviour of the mosquitoes in our study varied in between experiments. However, it is clear that in the presence of human skin residues there was neither an inhibitive nor an attractive effect of carbon dioxide on the entry responses of A. gambiae s.s. Therefore, the role of carbon dioxide in the host-seeking behaviour of $A$. gambiae s.s. is small compared to that of other human emanations. It is concluded that host-specific cues such as skin residues play a major role in host identification of $A$. gambiae s.s., whilst carbon dioxide plays a minor role.

\section{Acknowledgements}

This investigation received financial support from the UNDP/World Bank/WHO special Programme for Research and Training in Tropical Diseases (TDR). We would like to thank F. van Aggelen, A. Gidding and L. Koopmans for rearing the mosquitoes and Piet Kostense for drawing figure 1.

\section{References}

Braks, M.A.H. \& Takken, W. (1999) Incubated human sweat but not fresh sweat attracts the malaria mosquito Anopheles gambiae sensu stricto. Journal of Chemical Ecology 25, 663-672.

Braks, M., Cork, A. \& Takken, W. (1997) Olfactometer studies on the attraction of Anopheles gambiae sensu stricto (Diptera: Culicidae) to human sweat. Proceedings of the Experimental and Applied Entomology, NEV Amsterdam 8, 99-104.

Coluzzi, M., Sabatini, A. \& Petrarca, V. (1975) Chromosomal investigations on species $A$ and $B$ of the Anopheles gambiae complex in the Garki district (Kano State, Nigeria): results of species identifications from 1971 to 1974 . World Health Organization Technical note no. 24, MPD/TN/75.1, pp. 16-25.

Costantini, C., Gibson, G., Brady, J., Merzagora, L. \& Coluzzi, M. (1993) A new odour baited trap to collect host-seeking mosquitoes. Parassitologia 35, 5-9.

Costantini, C., Gibson, G., Sagnon, N., Della Torre, A., Brady, J. \& Coluzzi, M. (1996) Mosquito responses to carbon dioxide in a West African Sudan savanna village. Medical and Veterinary Entomology 10, 220-227.

Costantini, C., Sagnon, N., Della Torre, A., Diallo, M., Brady, J., Gibson, G. \& Coluzzi, M. (1998) Odour-mediated host preferences of West African mosquitoes, with particular reference to malaria vectors. American Journal of Tropical Medicine and Hygiene 58, 56-63.

De Jong, R. \& Knols, B.G.J. (1995) Selection of biting sites on man by two malaria mosquito species. Experientia 51, $80-84$.
Dekker, T. \& Takken, W. (1998) The role of carbon dioxide in host-seeking Anopheles gambiae sensu lato (Diptera: Culicidae). Proceedings of the Experimental and Applied Entomology, NEV Amsterdam 9, 23-28.

Dekker, T., Takken, W. \& Cardé, R.T. (in press) Structure of host-odour plumes influences upwind flight and trap catch of Anopheles gambiae s.s. and Aedes aegypti. Physiological Entomology

Diatta, M., Spiegel, A., Lochouarn, L. \& Fontenille, D. (1998) Similar feeding preferences of Anopheles gambiae and An. arabiensis in Senegal. Transactions of the Royal Society of Tropical Medicine and Hygiene 92, 270-272.

Geier, M., Sass, H. \& Boeckh, J. (1996) Search for components in human body odour that attract females of Aedes aegypti. Ciba Foundation Symposium 200, 132-144.

Gillies, M.T. (1967) Experiments on host selection in the Anopheles gambiae complex. Annals of Tropical Medicine and Parasitology 61, 68-75.

Gillies, M.T. (1980) The role of carbon dioxide in host finding by mosquitoes (Diptera: Culicidae): a review. Bulletin of Entomological Research 70, 525-532.

Hunt, R.H., Coetzee, M. \& Fettene, M. (1998) The Anopheles gambiae complex: a new species from Ethiopia. Transactions of the Royal Society of Hygiene and Tropical Medicine 92, 231-235.

Klowden, M.J. \& Lea, A.O. (1978) Blood meal size as a factor affecting continued host-seeking by Aedes aegypti (L.). American Journal of Tropical Medicine and Hygiene 27, 827-831.

Knols, B.G.J. \& De Jong, R. (1996) Limburger cheese as an attractant for the malaria mosquito Anopheles gambiae s.s. Parasitology Today 12, 159-161.

Knols, B.G.J., De Jong, R. \& Takken, W. (1994) Trapping system for testing olfactory responses of the malaria mosquito Anopheles gambiae in a wind tunnel. Medical and Veterinary Entomology 8, 386-388.

Knols, B.G.J., De Jong, R. \& Takken, W. (1995) Differential attractiveness of isolated humans to mosquitoes in Tanzania. Transactions of the Royal Society of Tropical Medicine and Hygiene 89, 604-606.

Knols, B.G.J., Van Loon, J.J.A., Cork, A., Robinson, R.D., Adam, W., Meijerink, J., De Jong, R. \& Takken, W. (1997) Behavioural and electrophysiological responses of the female malaria mosquito Anopheles gambiae (Diptera: Culicidae) to Limburger cheese volatiles. Bulletin of Entomological Research 87, 151-159.

Mboera, L.E.G. \& Takken, W. (1997) Carbon dioxide chemotropism in mosquitoes (Diptera: Culicidae) and its potential in vector surveillance and management programmes. Review of Medical and Veterinary Entomology 85, 355-368

Mboera, L.E.G., Knols, B.G.J., Takken, W. \& Della Torre, A. (1997) The response of Anopheles gambiae s.l. and A. funestus (Diptera: Culicidae) to tents baited with human odour or carbon dioxide in Tanzania. Bulletin of Entomological Research 87, 173-178.

Mboera, L.E., Knols, B.G., Takken, W. \& Huisman, P.W. (1998) Olfactory responses of female Culex quinquefasciatus Say (Diptera: Culicidae) in a dual choice olfactometer. Journal of Vector Ecology 23, 107-113.

Takken, W. \& Knols, B.G.J. (1990) Flight behaviour of Anopheles gambiae Giles (Diptera: Culicidae) in response to host stimuli: a windtunnel study. Proceedings of the Experimental and Applied Entomology, NEV Amsterdam 1, 121-128. 
Takken, W. \& Knols, B.G.J. (1999) Odour-mediated behavior of Afrotropical malaria mosquitoes. Annual Review of Entomology 44, 131-157.

Takken, W., Dekker, T. \& Wijnholds, Y. (1997) Odour-mediated flight behavior of Anopheles gambiae Giles sensu stricto and An. stephensi Liston in response to $\mathrm{CO}_{2}$, acetone and 1octen-3-ol (Diptera: Culicidae). Journal of Insect Behaviour 10, 395-407.

White, G.B. (1974) Anopheles gambiae complex and disease transmission in Africa. Transactions of the Royal Society of Tropical Medicine and Hygiene 68, 278-301.

White, G.B. (1985) Anopheles bwambae sp., a malaria vector in the
Semliki Valley, Uganda, and its relationships with other sibling species of the An. gambiae complex (Diptera: Culicidae). Systematic Entomology 10, 501-522.

White, G.B. \& Rosen, P. (1973) Comparative studies on sibling species of the Anopheles gambiae Giles complex (Dipt., Culicidae). II. Ecology of species A and B in savanna around Kaduna, Nigeria, during transition from wet to dry season. Bulletin of Entomological Research 62, 613-625.

(Accepted 8 March 2001)

(C) CAB International, 2001 